\title{
One Year Randomized Study of L-Thyroxin Treatment in Women with Subclinical Hypothyroidism
}

\author{
Olfat A. Fawzy ${ }^{1}$, Eman Mahmoud ${ }^{1}$, Wael M. Attia ${ }^{2}$, Ahmed M. Ibrahim ${ }^{3}$ \\ ${ }^{1}$ Department of Endocrinology, Faculty of Medicine for Girls, Al-Azhar University, \\ ${ }^{2}$ Department of Cardiology, Faculty of Medicine for Boys, Al-Azhar University, \\ ${ }^{3}$ Police Authority Hospital, Ministry of Interior, Cairo, Egypt \\ *Corresponding author: Ahmed Morsy Ibrahim, E-mail: drahmedmorsy @ yahoo.com, Mobile: (+20)01223955647
}

\begin{abstract}
Introduction: Subclinical hypothyroidism ( $\mathrm{SCH}$ ) is a laboratory finding which may be asymptomatic or associated with signs and symptoms of hypothyroidism. However, benefits of L-Thyroxin (LT4) treatment are not well established.
\end{abstract}

Aim of the Work: The aim of the study was to evaluate the impact of treatment of SCH on thyroid clinical scores, bone mineral density (BMD), cardiac function and health related quality of life (HR-QOL).

Subjects and Methods: a total number of 65 women, who were diagnosed with SCH, constituted the study subjects. They were within the age range of 40-70 years. They were randomly divided into two groups (group I, included 25 patients who were treated with L Thyroxin (L-T4), and group II included 40 women with SCH who were not treated and kept under follow up for one year. Effects of L-T4 treatment on BMI, cardiac function, BMD, lipid profile, thyroid clinical score and HR-QOL were assessed.

Results: After one year; regarding body mass index (BMI), Group II had significantly higher BMI ( $\mathrm{p}=0.006)$ though the percentage change of BMI after one year was comparable in the two groups. Total thyroid clinical score and the total HR-QOL score were significantly lower in Group I compared to group II ( $p<0.001)$. Regarding thyroid hormone profile; free T4 was significantly higher and thyroid stimulating hormone (TSH) was significantly lower in-group I compared to group II ( $\mathrm{p}=0.033 \& \mathrm{p}<0.001$ respectively).

Conclusion: LT4 treatment for women with SCH was found to improve total clinical thyroid score, HR-QOL, systolic and diastolic dysfunction besides lowering TC, LDL and TG levels. However, there was evidence of bone loss in patients with SCH treated with L-T4. Thus, decision to treat or not should be individualized according to the patient's risk benefit ratio assessment.

Keywords: Subclinical Hypothyroidism, Thyroid Clinical Score, Diastolic Dysfunction, Health Related Quality of Life.

\section{INTRODUCTION}

Subclinical hypothyroidism ( $\mathrm{SCH}$ ), also called mild thyroid failure, is diagnosed when peripheral thyroid hormone levels (FT4) are within normal reference laboratory range but serum thyroidstimulating hormone (TSH) levels are mildly elevated corrected by age, as suggested by the American and European thyroid associations and the American Association of Clinical Endocrinology (1, 2).

The incidence of SCH is $4-10 \%$ and is higher in women. The prevalence of $\mathrm{SCH}$ significantly increases in people over the age of 60 when it reaches $15 \%$ of females and $8 \%$ of males ${ }^{(3)}$. The commonest leading cause of increased TSH is chronic autoimmune thyroiditis ${ }^{(4)}$. Among the patients with the TSH values of 5.0-9.9 $\mathrm{mIU} / \mathrm{L}, \mathrm{SCH}$ progresses to overt hypothyroidism in $5.6 \%$ of cases. Patients with TSH values between 15.0 and $19.9 \mathrm{mIU} / \mathrm{L}$ have a higher percentage of progression $(85.7 \%)^{(1,5)}$.

According to current guidelines, a decision for treatment is based on the presence of mild symptoms suggestive of hypothyroidism as goiter and any other comorbidity. Many authors advise LThyroxine (LT4) treatment only if TSH elevation still persists for more than 3 months and the patient has other risk factors for developing overt hypothyroidism ${ }^{(6)}$.

Several studies have reported a link between $\mathrm{SCH}$ and conditions that increase morbidity and mortality rates, such as weight gain, quality of life, diastolic hypertension, low-grade inflammation, low fat lipid level, insulin resistance, and metabolic syndrome and heart dysfunction. L-T4 may have positive effects on many of these associated diseases ${ }^{(1,3-9)}$. The aim of the current work was to evaluate the impact of treatment of subclinical hypothyroidism on thyroid clinical scores, bone mineral density, cardiac function and health related quality of life.

\section{PATIENTS AND METHODS}

This prospective follow up study included a total of 65 women, who were diagnosed with subclinical hypothyroidism ( $\mathrm{SCH}$ ). They were recruited from the outpatient clinics of Al-Agouza Hospital in Giza. Approval of the ethical committee and a written informed consent from all the subjects were obtained. This study was conducted between January 2014, and December 2018. 
Patients were within the age range of 40-70 years. Females only were included to exclude possible impact of sex on studied variables. They were all ambulating and in good general condition. Inclusion criteria included also a TSH value between 4.2 to $9.9 \mathrm{mU} / \mathrm{L}$ which is the cut off value for diagnosis of $\mathrm{SCH}$ according to Khandelwal and Tandon in 2012(10). Exclusion criteria included history of smoking, coronary artery disease, uncontrolled hypertension, chronic obstructive pulmonary disease, bronchial asthma, diabetes, familial hypercholesterolemia, atrial fibrillation, moderate to severe valvular heart disease, cardiomyopathy, previous hyperthyroidism and previous use of lipid lowering agent in last 6 months.

\section{Patients were divided into two groups:}

- Group I: included 25 patients with SCH who were subjected to L-T4 treatment starting by $25 \mathrm{mcg}$ per day. Serum TSH level was assessed monthly for dose adjustment for one year. $50 \mathrm{mcg}$ per day was the maximum of L-T4 dose reached adjusted for each patient to keep TSH value in the normal range $<4.2 \mathrm{mU} / 1$.

- Group II: included 40 Patients with SCH who were kept under clinical monitoring and follow up without treatment. Serum TSH level was monitored for one year.

\section{All participants were subjected to the following at} baseline and after one year of the study period:

1. Complete medical history including age, menstrual history, fertility, parity, and family history.

2. Signs and symptoms of thyroid dysfunction were assessed using Zulewski thyroid clinical score ${ }^{(\mathbf{1 1})}$.

3. Body mass index (BMI) for all subjects.

4. Health related Quality of life (HR-QOL) was assessed using the SF-36 questionnaire ${ }^{(\mathbf{1 2})}$.

5. The following laboratory investigations including complete blood picture, lipid profile. thyroid profile (FT3, FT4, TSH and anti-thyroid peroxidase antibodies; anti TPO).

6. Bone mineral density (BMD) using Dual energy Xray absorptiometry (DEXA) scans.

7. Echocardiography examination assessed systolic parameters; including ejection fraction (EF), fraction shortening (FS) ${ }^{(13)(14)}$ and Myocardial Performance Index (MPI) (Tie index) which is defined as the sum of isovolumetric contraction (IVCT) and relaxation time (IVRT) divided by the ejection time (ET). Diastolic parameter was assessed by calculating E/A ratio as follows; Peak E (left ventricular peak early transmural flow velocity)/ Peak A (left ventricular peak late transmural flow velocity) ${ }^{(15)}$.

\section{Statistical Analysis}

All the data were collected, revised, coded and entered to the Statistical Package for Social Science (IBM SPSS) version 23. The quantitative data were presented as mean, standard deviations and ranges when their distribution was found to be parametric while qualitative data were presented as number and percentages using Student t-test for normally distributed data or Mann-Whitney test (non-parametric t-test) for not normally distributed data. Mc-Nemar test was used for two consecutive measures of qualitative variables. All tests were twotailed. Spearman-rho method was used to test correlation between numerical variables and presented as correlation coefficient (r) and p-value. The confidence interval was set to $95 \%$ and error margin accepted was set to $5 \%$. The p-value was considered significant as the following: $\mathrm{P}>0.05$ : Non-significant $\mathrm{P}<0.05$ : Significant

\section{RESULTS}

Regarding body mass index (BMI), Group II had significantly higher BMI at baseline compared to Group I $(\mathrm{p}=0.005)$ as well as after one year $(p=0.006)$. The percentage change of BMI after one year was comparable in the two groups (table 1). Frequency of symptoms of all SCH patients was comparable between the studied groups at baseline including; paresthesia, diminished sweating, hoarseness of voice, dry skin, weight gain, and constipation. After 1 year, the frequency of hypothyroid symptoms was comparable between the treated and untreated groups (figure 1), signs of all $\mathrm{SCH}$ patients at baseline were comparable including; coarse skin, cold skin, periorbital puffiness and delayed ankle jerk reflex. Total thyroid clinical score was comparable in the two groups at baseline, but it was significantly lower in Group I after 1 year ( $<<0.001)$ (table 1). Regarding HR-QOL, at baseline scores of physical function, role physical, bodily pain, general health, emotional role, mental health, vitality and social function were comparable between the two studied groups. After one year; scores of the physical function, role physical, bodily pain, general health, emotional role, mental health, and vitality were significantly improved in Group I compared to Group II ( $p<0.001)$, except for the score of social function domain which was comparable in the two groups (figure 2). The total HR-QOL at baseline was significantly higher in Group II compared to group I ( $\mathrm{p}=0.047)$. After oneyear, total HR-QOL was significantly higher in Group I ( $p<0.001)$ and the percentage of change was significantly higher in Group I after one year ( $p$ $<0.001)$ (table 1). 


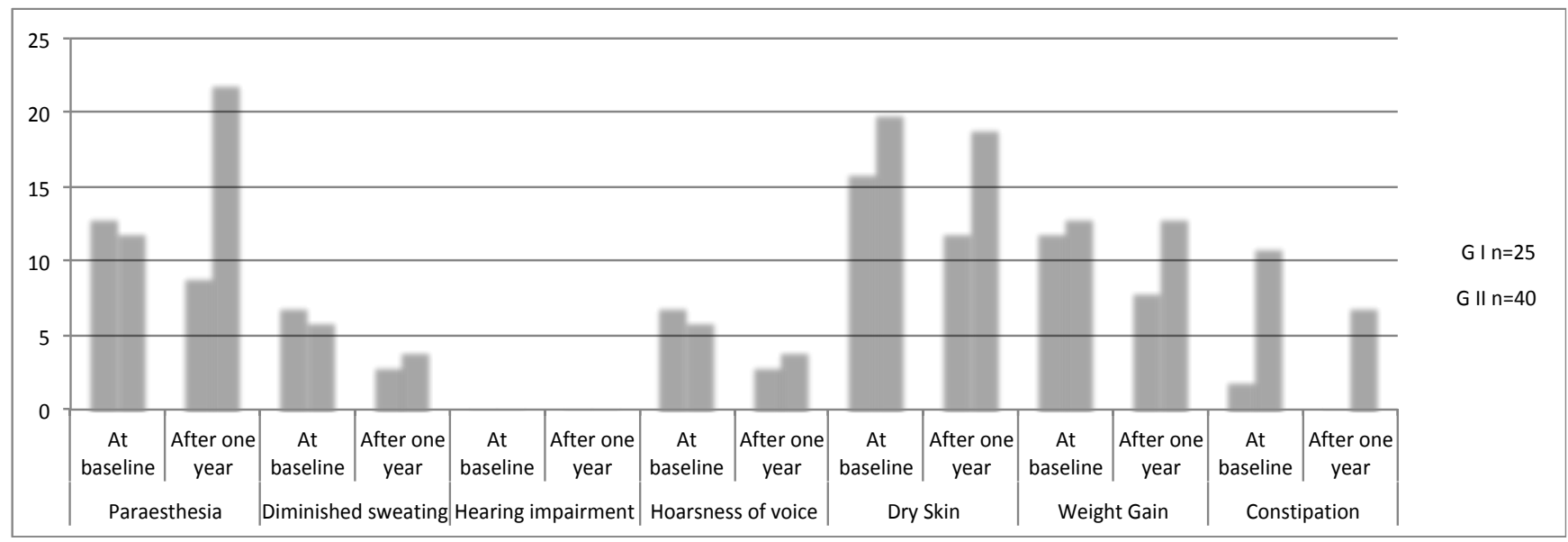

Figure1: Symptoms of hypothyroidism at baseline and after one year in the two studied groups

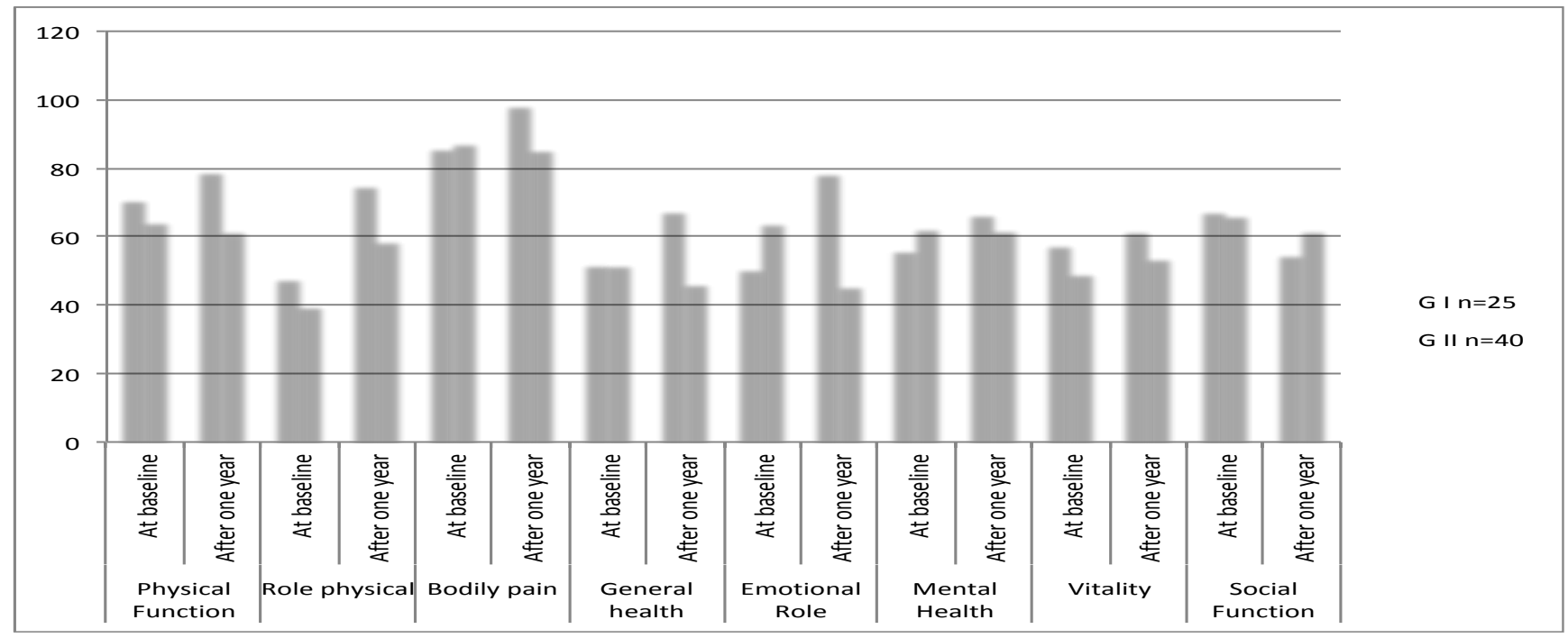

Figure 2: Health related Quality of life scoring by the SF-36 questionnaire at baseline and after one year in the two studied groups

Table (1): Body mass Index, Thyroid Clinical Score and total quality of life score at baseline and after one year in two studied groups

\begin{tabular}{|l|c|c|c|c|c|c|c|c|c|}
\hline & \multicolumn{3}{|c|}{$\begin{array}{c}\text { Body mass Index } \\
\left(\mathbf{k g} / \mathbf{m}^{\mathbf{2}}\right)\end{array}$} & \multicolumn{3}{c|}{$\begin{array}{c}\text { Thyroid Clinical } \\
\text { Score }\end{array}$} & \multicolumn{3}{c|}{$\begin{array}{c}\text { Total quality } \\
\text { of life score }\end{array}$} \\
\cline { 2 - 11 } & $\begin{array}{c}\text { Group I I } \\
\mathbf{n = 2 5}\end{array}$ & $\begin{array}{c}\text { Group II } \\
\mathbf{n = 4 0}\end{array}$ & $\mathbf{p}$ value & $\begin{array}{c}\text { Group I } \\
\mathbf{n = 2 5}\end{array}$ & $\begin{array}{c}\text { Group II } \\
\mathbf{n = 4 0}\end{array}$ & p value & $\begin{array}{c}\text { Group I } \\
\mathbf{n = 2 5}\end{array}$ & $\begin{array}{c}\text { Group II } \\
\mathbf{n = 4 0}\end{array}$ & p value \\
\hline At baseline & 32.4 & 35.7 & 0.005 & 4.0 & 4.0 & 0.393 & 108.5 & 110.3 & 0.047 \\
\hline After 1 y & 34.2 & 34.8 & 0.006 & 3.0 & 4.0 & $<0.001$ & 113.7 & 107.2 & $<0.001$ \\
\hline \%Change & 0 & 0 & 0.479 & -2.0 & 0.0 & $<0.001$ & 5.0 & -5.5 & $<0.001$ \\
\hline
\end{tabular}


Regarding thyroid hormone profile; at baseline there was no significant difference between the two groups as regards free T3, free T4 and TSH. After one-year, free T4 was significantly higher and TSH was significantly lower in-group I compared to group II ( $\mathrm{p}=0.033,<0.001$ respectively). The percentage change of TSH was significantly higher in Group I compared to group 2 ( $\mathrm{p}<0.001)$ (table 2$)$.
Regarding lipid profile; at baseline, the two groups had comparable levels of triglycerides, total cholesterol, LDL and HDL. After one year, Group I had significantly lower levels of triglycerides, total cholesterol, and LDL.

Percentage change of triglycerides, total cholesterol, and LDL decreased significantly in Group I compared to Group II. However, HDL levels after one year were comparable in the two groups $(\mathrm{p}=0.060)($ table 2$)$.

Table (2): Laboratory investigation at diagnosis and after one year and two study groups:

\begin{tabular}{|c|c|c|c|c|c|c|c|c|c|}
\hline & \multicolumn{3}{|c|}{$\begin{array}{r}\text { Free T3 } \\
(\mathrm{pg} / \mathrm{ml})\end{array}$} & \multicolumn{3}{|c|}{$\begin{array}{c}\text { Free T4 } \\
\text { (ng/dL) }\end{array}$} & \multicolumn{3}{|c|}{$\begin{array}{r}\text { TSH } \\
(\mu \mathrm{U} / \mathbf{m L})\end{array}$} \\
\hline & $\begin{array}{r}\text { G1 } \\
25\end{array}$ & $\begin{array}{r}\text { G2 } \\
40\end{array}$ & $\begin{array}{r}P \\
\text { value }\end{array}$ & $\begin{array}{r}\text { G1 } \\
25\end{array}$ & $\begin{array}{r}\text { G2 } \\
40\end{array}$ & $\begin{array}{r}\mathbf{P} \\
\text { value }\end{array}$ & $\begin{array}{r}\text { G1 } \\
25\end{array}$ & $\begin{array}{r}\text { G2 } \\
40\end{array}$ & $\begin{array}{r}P \\
\text { value }\end{array}$ \\
\hline $\begin{array}{l}\text { At } \\
\text { baseline }\end{array}$ & 1.9 & 2.0 & 0.583 & 1.0 & 1.0 & 0.373 & 6.9 & 6.9 & 0.893 \\
\hline After 1Y & 2.0 & 1.8 & 0.321 & 1.1 & 0.9 & 0.033 & 2.9 & 7.5 & $<0.001$ \\
\hline$\%$ change & 1.8 & 1.9 & 0.393 & 0.1 & 0.0 & 0.171 & -3.9 & -0.2 & $<0.001$ \\
\hline
\end{tabular}

\begin{tabular}{|c|c|c|c|c|c|c|c|c|c|c|c|c|}
\hline & \multicolumn{3}{|c|}{$\begin{array}{r}\text { Triglycerides } \\
\text { (mg/dL) }\end{array}$} & \multicolumn{3}{|c|}{$\begin{array}{r}\text { Total } \\
\text { Cholesterol } \\
(\mathbf{m g} / \mathbf{d L}) \\
\end{array}$} & \multicolumn{3}{|c|}{$\begin{array}{r}\text { LDL } \\
(\mathrm{mg} / \mathrm{dL})\end{array}$} & \multicolumn{3}{|c|}{$\begin{array}{r}\text { HDL } \\
(\mathrm{mg} / \mathrm{dL})\end{array}$} \\
\hline & $\begin{array}{r}\text { G1 } \\
25\end{array}$ & $\begin{array}{r}\text { G2 } \\
40\end{array}$ & $\begin{array}{r}P \\
\text { value }\end{array}$ & $\begin{array}{r}\text { G1 } \\
25\end{array}$ & $\begin{array}{r}\text { G2 } \\
40\end{array}$ & $\begin{array}{r}P \\
\text { value }\end{array}$ & $\begin{array}{r}\text { G1 } \\
25\end{array}$ & $\begin{array}{r}\text { G2 } \\
40\end{array}$ & $\begin{array}{r}P \\
\text { value }\end{array}$ & $\begin{array}{r}\text { G1 } \\
25\end{array}$ & $\begin{array}{r}\text { G2 } \\
40\end{array}$ & $\begin{array}{r}\mathbf{P} \\
\text { value }\end{array}$ \\
\hline $\begin{array}{l}\text { At } \\
\text { baseline }\end{array}$ & 140.3 & 141.4 & 0.879 & 198.7 & 204.3 & 0.659 & 134.7 & 126.5 & 0.282 & 41.0 & 42.4 & 0.438 \\
\hline After 1Y & 97.3 & 149.3 & $<0.001$ & 170.8 & 246.7 & $<0.001$ & 95.7 & 192.3 & 0.001 & 40.0 & 37.8 & 0.245 \\
\hline$\%$ change & -41.0 & 10.0 & $<0.001$ & -28.0 & 61.5 & $<0.001$ & -30.0 & 79.0 & $<0.001$ & -1.0 & -6.0 & 0.060 \\
\hline
\end{tabular}

P-value > 0.05: Non significant; P-value < 0.05: Significant. LDL: low density lipoprotein, HDL: high-density lipoprotein 
Regarding cardiac function; no significant difference was found between the two groups regarding fractional shortening and Tie index at baseline and after one year. E/A ratio was comparable in the two groups at baseline. However, after one year, E/A ratio as well as the percentage change in E/A ratio were significantly higher in Group I compared to Group II ( $\mathrm{p}<0.001$ ). Ejection fraction percentage change increased significantly in Group I with treatment $(\mathrm{p}=0.035)$ (table 3$)$.

Table (3): Echocardiographic characteristics at diagnosis and after one year in the two studied groups

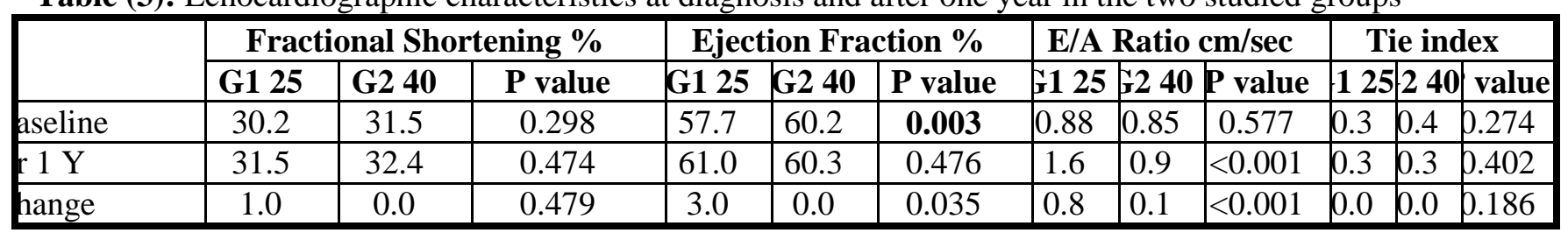

E/A: LV peak early transmural flow velocity; LV peak late transmural flow velocity

Regarding BMD; at baseline, the two groups had comparable $\mathrm{T}$ and $\mathrm{Z}$ scores in the right hip and spine. $\mathrm{Z}$ scores of the right hip and spine were significantly lower in Group I after one year ( $p=0.003,0.001$ respectively). The $\mathrm{Z}$ scores change of the right hip and spine differed significantly in Group I compared to group 2 ( $\mathrm{p}=0.037$, 0.010 respectively). $T$ score of the spine was significantly lower in Group I after one year $(\mathrm{p}<0.001)$. The T score change of the spine differed significantly in Group I ( $\mathrm{p}=0.001)$ (table 4).

Table (4): $\mathrm{T}$ and $\mathrm{Z}$ scores of the right hip and spine at baseline and after one year in the two studied groups

\begin{tabular}{|c|c|c|c|c|c|c|c|c|c|c|c|c|c|c|}
\hline & \multicolumn{7}{|c|}{ Right Hip } & \multicolumn{7}{|c|}{ Spine } \\
\hline & \multicolumn{3}{|c|}{ G I $n=25$} & \multicolumn{3}{|c|}{ G II $n=40$} & \multirow{2}{*}{ P value } & \multicolumn{3}{|c|}{ G I n $=25$} & \multicolumn{3}{|c|}{ G II $n=40$} & \multirow{2}{*}{$P$ value } \\
\hline & Median & Min. & Max. & Median & Min. & Max. & & Median & Min. & Max. & Median & Min. & Max. & \\
\hline$T$ score at baseline & \begin{tabular}{|l|}
-1.2 \\
\end{tabular} & -2.2 & -0.2 & -1.2 & -2.2 & 0.6 & 0.699 & -1.8 & -2.3 & -0.5 & -1.8 & -2.3 & -0.2 & 0.894 \\
\hline T score after 1 year & -1.5 & -2.5 & -0.5 & -1.2 & -2.5 & -0.2 & 0.064 & -2.0 & -2.7 & -0.7 & -1.5 & -2.4 & -0.2 & $<0.001$ \\
\hline T score change & -0.1 & -1.8 & 1.4 & 0.0 & -2.1 & 1.7 & 0.380 & -0.4 & -1.3 & 0.6 & 0.0 & -1.3 & 1.9 & $\underline{\underline{0.001}}$ \\
\hline$Z$ score at baseline & -1.2 & -2.1 & 0.4 & -1.0 & -2.3 & 1.1 & 0.490 & -1.3 & -2.4 & 0.4 & -1.3 & -2.4 & 0.3 & $\overline{0.863}$ \\
\hline$Z$ score after 1 year & -1.2 & -2.4 & -0.1 & -0.4 & -2.5 & 1.0 & $\underline{0.003}$ & -1.8 & -2.8 & 0.2 & -0.7 & -2.0 & 0.4 & $\underline{0.001}$ \\
\hline Z score change & -0.1 & -1.6 & 1.5 & 0.0 & -1.8 & 1.8 & 0.037 & -0.2 & -1.9 & 1.0 & 0.1 & -1.3 & 2.6 & $\underline{0.010}$ \\
\hline
\end{tabular}

There was significant positive correlation between and the percentage change in LDL, total clinical score, spine T score and TG, while there was negative significant correlation between TSH percentage change and E/A ratio, and no significant correlation was observed with BMI and total QOL (table 5 and figure 4).

Table (5): Correlation between serum TSH percentage change and different variable outcomes percentage change in all $\mathrm{SCH}$ patients in the present study

\begin{tabular}{|l|c|c|}
\hline \multirow{2}{*}{ Spearman rho } & \multicolumn{2}{|c|}{ TSH (65 patients) } \\
\cline { 2 - 3 } & $\mathbf{r}$ & $\mathbf{P}$ \\
\hline LDL & 0.616 & $<\mathbf{0 . 0 0 1}$ \\
\hline E/A & -0.657 & $<\mathbf{0 . 0 0 1}$ \\
\hline Total Clinical Score & 0.508 & $<\mathbf{0 . 0 0 1}$ \\
\hline Spine T score & 0.284 & $\mathbf{0 . 0 2 2}$ \\
\hline TG & 0.325 & $\mathbf{0 . 0 0 8}$ \\
\hline Total QOL & 0.027 & 0.830 \\
\hline & 0.156 & 0.216 \\
\hline
\end{tabular}

P-value > 0.05: Non significant; P-value < 0.05: Significant. 
One Year Randomized Study of L-Thyroxin Treatment ...

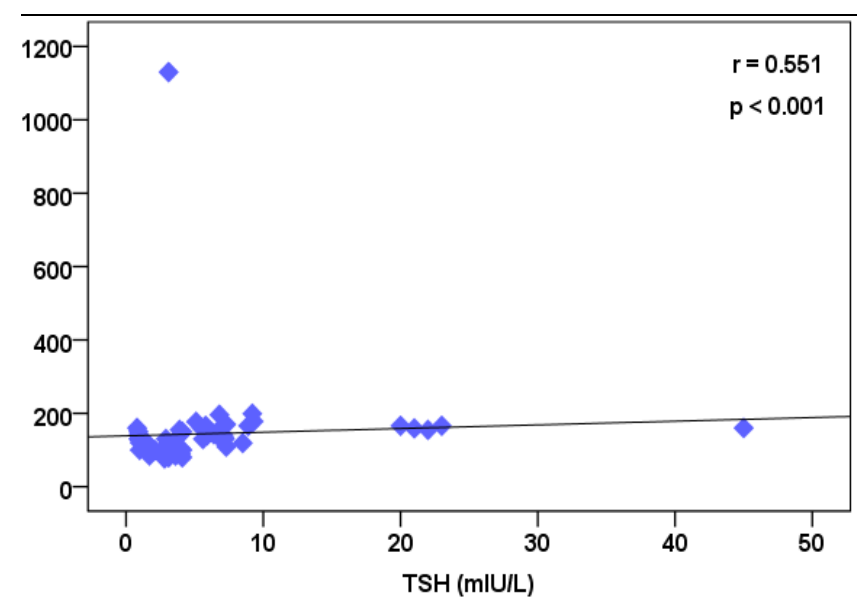

Figure 4(a): Correlation of TSH and TG

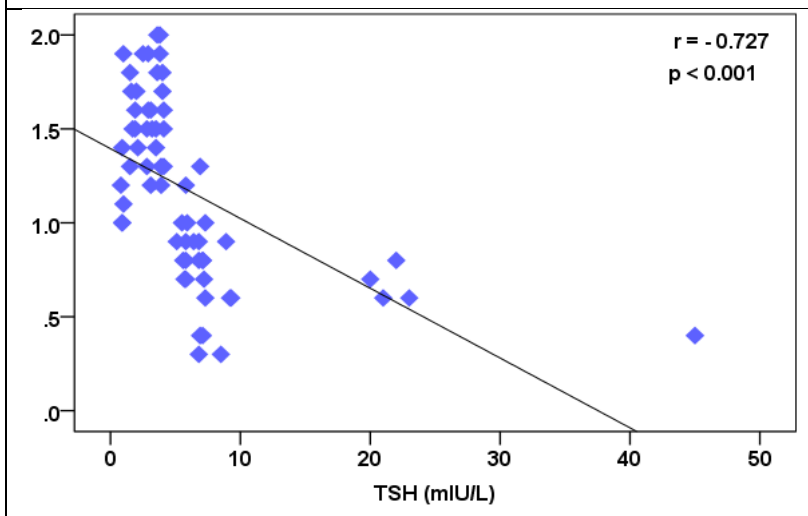

Figure 4(c): Correlation of TSH and E/A ratio

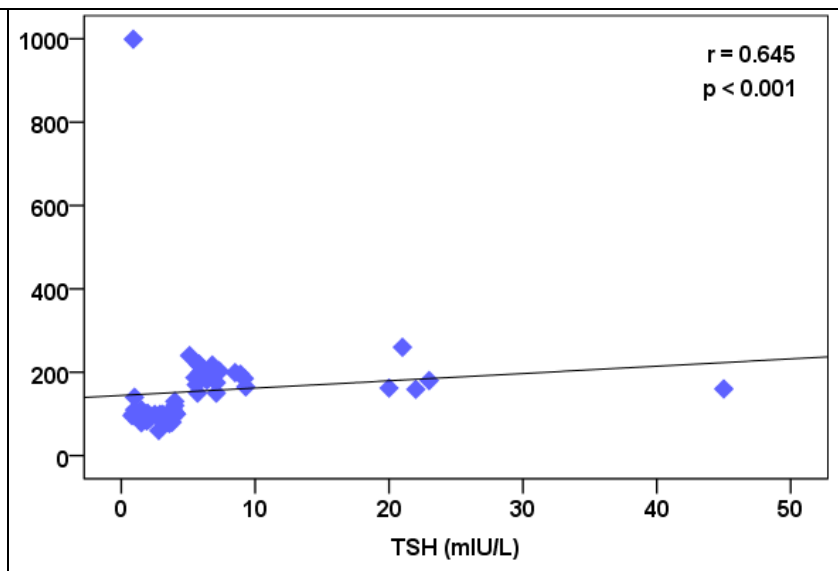

Figure 4(b): Correlation of TSH and LDL

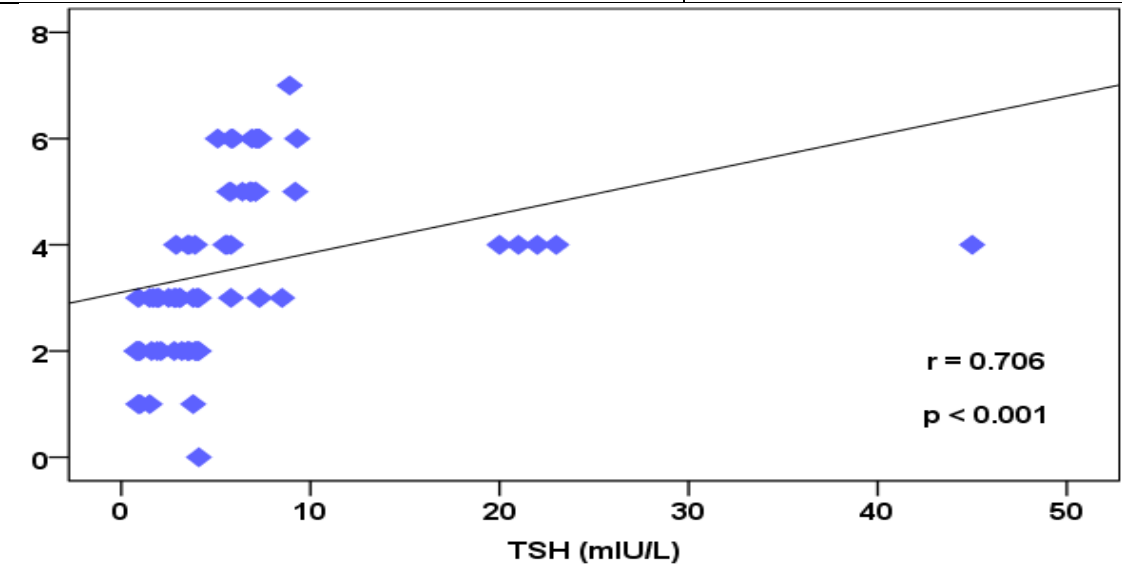

Figure 4 (e): Correlation of TSH and Total Clinical score 


\section{DISCUSSION}

The present study is a prospective follow up study done to evaluate the impact of treatment of $\mathrm{SCH}$ on thyroid clinical scores, BMD, cardiac function and HR-QOL of life.

In the present study; regarding the clinical characteristics of the study population; at baseline all SCH patients had high BMI; mean was above 30, but group II has significantly higher BMI $(\mathrm{p}=0.005)$. Gupta and his colleagues, in 2015, stated that women with $\mathrm{SCH}$ have higher BMI due to their increased body weight compared to healthy subjects ${ }^{(16)}$.

Pesic et al (2014) confirmed a correlation between TSH and BMI ${ }^{(3)}$. On the other hand, Karthick and his colleagues, in 2013, found that compared to euthyroid people, patients with SCH had lower BMI ${ }^{(17)}$. In the present study after one year; all SCH patients still had high BMI; mean was above 30, but untreated women had significantly higher BMI $(p=0.005)$. Though LT-4 treatment didn't affect BMI significantly in group I but BMI was still significantly higher in group II after 1 year $(\mathrm{p}=0.006)$. Similarly, Ito et al (2013) stated that restoration of thyroid function does not seem to have significant effect on BMI, in individuals with $\mathrm{SCH}{ }^{(18)}$. Also, Pandrc and her colleagues in 2017, in a prospective study on $\mathrm{SCH}$ patients, reported no reduction in BMI during L-T4 replacement therapy ${ }^{(\mathbf{1 9})}$.

In the present study using Zulewski score, symptoms were comparable between the two studied groups at baseline and after one year in the treated and untreated groups except for constipation that was significantly lower in Group I (p <0.001). Jorde et al in 2006 found no difference in symptoms of hypothyroidism between SCH individual having TSH $<10 \mathrm{mIU} / \mathrm{l}$ compared with healthy controls except for tiredness (20). Another study found no significant difference in symptoms in patients with $\mathrm{SCH}$ and euthyroid controls ${ }^{(21)}$. Signs of hypothyroidism were comparable in all SCH patients at baseline and after one year. Total thyroid clinical score was comparable in both groups at baseline. However, thyroid score decreased significantly in-group I after treatment ( $p$ $<0.001$ ) denoting improving symptoms and signs after L-T4 treatment. Meier and his associates in 2004 investigated the effect of L-T4 treatment on clinical symptoms in patients with $\mathrm{SCH}$ using two clinical scores assessing symptoms and signs of hypothyroidism (Billewicz and Zulewski scores) and concluded that signs and symptoms improved significantly with L-T4 treatment ${ }^{(22)}$. However, in other randomized trials which studied the effect of L-T4 therapy on clinical symptoms in individuals with mild $\mathrm{SCH}$, evidence was insufficient to support L-T4 treatment in mild SCH. They concluded that benefits seen in the available trials are either very minor or of no benefit ${ }^{(23)}$. In a randomized double-blind study, Reuters and his colleagues in 2012 investigated the impact of $\mathrm{SCH}$ treatment on clinical score. Clinical symptoms were assessed using Zulewski, Hamilton and Beck scales. They concluded that $\mathrm{SCH}$ treatment improved clinical score, but that might be more due to "placebo

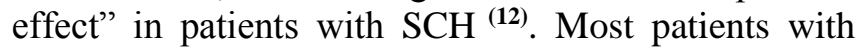
mild- SCH have either very few or no symptoms and there is some evidence, but insufficient, of improvement in tiredness by L-T4 treatment ${ }^{(\mathbf{1 6})}$.

Both the measurement and improvement of HR-QOL are currently becoming an increasingly important part of patient-centered care ${ }^{(24)}$. The influence of SCH on health status or HR-QOL was not well established. Some population studies reported no differences in HR-QOL perception between SCH individuals and a normal population ${ }^{(25)}$. In the present study, at baseline scores were comparable between the two studied groups. All domains were near 50 reflecting average health except for vitality which was higher in group I compared to group II (p <0.001). In 2013, Klaver and his associates found that HR-QOL scores of subjects with suppressed TSH values or markedly elevated TSH values were generally not significantly lower than those of individuals with normal or mildly elevated TSH values ${ }^{(24)}$. In the present study after one year, scores of the physical function, role physical, bodily pain, general health, emotional role, mental health, and vitality were significantly higher in Group I compared to Group II ( $\mathrm{p}<0.05)$.

Only, the score of social function domain was comparable in the two groups. These findings suggest that L-T4 treatment may improve HR-QOL. However, no correlation was found between total HR-QOL percentage change with TSH percentage change. This could be attributed to the normal average domains of HR-QOL in all studied patients at baseline. In agreement, Pandrc and her associates measured HRQOL before and 3 months after treatment, when normal thyroid function was achieved in $\mathrm{SCH}$ patients. They concluded that, HR-QOL was improved, and correlated only with L-T4 treatment ${ }^{(20)}$. However, Reuters et al (2012) evaluated the impact of SCH treatment on HRQOL and found that SCH treatment only improved physical aspects of HR-QOL ${ }^{(12)}$. 
Reduced BMD is associated with higher FT4 and FT3 levels, and higher FT4 levels are linked with increased bone loss at the hip ${ }^{(26)}$.

Garin and her associates did not find a relation between $\mathrm{SCH}$ and increased risk of hip fracture or lower $\mathrm{BMD}$ at the spine or hip in elderly men or women in a large, population-based cohort study ${ }^{(27)}$. In the present study, at baseline the two groups had comparable $\mathrm{T}$ and $\mathrm{Z}$ scores in the right hip ( $\mathrm{p}=0.699,0.490$ respectively) and spine $T$ and $Z$ scores ( $\mathrm{p}=0.849,0.863$ respectively). However, after one year, $\mathrm{Z}$ scores of the right hip and spine were significantly lower in Group I after treatment ( $\mathrm{p}=0.003,0.001$ respectively).

$\mathrm{T}$ score of the spine was also significantly lower in Group I after treatment ( $p<0.001)$. These results signify that L-T4 treatment negatively affects BMD. In agreement with our results, Meier and his associates in 2004 studied the effect of L-T4 treatment on bone metabolism in patients with $\mathrm{SCH}$ and concluded that L-T4 treatment resulted in significant activation of bone turnover ${ }^{(24)}$.

Lopez and his associates in 2011 also evaluated the prevalence of osteoporosis in $\mathrm{SCH}$ patients being treated with thyroid hormone and concluded that lumbar BMD was lower in L-T4 treated women ${ }^{(28)}$.

Swathi et al. (2014) observed a loss of bone mineral density in patients on long term treatment of levothyroxine. However, they did not report higher fracture rate due to decrease of TSH levels ${ }^{(29)}$.

Regarding $\mathrm{SCH}$ and dyslipidemia, many authors studied the relationship between $\mathrm{SCH}$ and dyslipidemia ${ }^{(30)}$. In the present study at baseline, the two groups had elevated but comparable levels of TG, TC, LDL, with average HDL levels.

Similarly, Pesic et al. in 2014, reported significantly increased TC, TG in patients with $\mathrm{SCH}$ as compared to the healthy individuals. They also observed that the frequency of all metabolic syndrome components was higher in $\mathrm{SCH}$ patients than in healthy patients, but the difference was statistically significant only in the arm of decreased HDL cholesterol ${ }^{(3)}$.Kota and his colleagues in 2012 revealed significant positive correlation of TSH with TG, TC, LDL and significant negative correlation with $\mathrm{HDL}^{(31)}$.

However, Caraccio et al. reported reductions in serum TC and LDL concentrations, in individuals having slightly elevated serum TSH level $(<10 \mathrm{mU} / \mathrm{l})$ ${ }^{(32)}$. In the present study after one year, triglycerides, total cholesterol, and LDL decreased significantly with treatment compared to the untreated group $(\mathrm{p}<0.001)$. HDL levels after one year were comparable in the two groups. In 2017, Pandrc and her associates also reported significant reduction in lipid parameters (TC, LDL and
TG) after 3 months of L-T4 treatment in SCH patients (20).

However, Anagnostis and his associates in 2014 found no significant changes in body weight, TC, LDL, HDL, TG levels after restoration of thyroid function with treatment ${ }^{(33)}$.

Regarding cardiac function; Preethi and Sripriya studied the echocardiographic cardiovascular changes in both overt clinical and asymptomatic SCH and reported diastolic dysfunction in 10\% of the studied groups. While EF and FS were not significantly associated, E/A was significantly associated with the severity of hypothyroidism ${ }^{(34)}$.

In the present study, at baseline FS, Tie index and E/A ratio were within normal in all patients and were comparable in two groups, EF also was within normal range in all patients but was significantly lower in group I compared to group II ( $\mathrm{p}=0.003)$.

After one year, no significant difference was also found between the two groups regarding FS and Tie index. However, the ejection fraction increased significantly with treatment $(\mathrm{p}=0.035)$ and $\mathrm{E} / \mathrm{A}$ ratio was significantly higher in Group I compared to Group II $(p<0.001)$, denoting that L-T4 treatment might improve systolic and diastolic function. In 2011 Martins and his colleges studied the effects of L-T4 treatment in echocardiographic parameters of middle-aged women with $\mathrm{SCH}$ and concluded that there was a positive impact of L-T4 replacement in cardiac function with $\mathrm{SCH}^{(13)}$.

In 2015, Shatynska and his associates assessed the impact of treatment with low doses of L-T4 (6.25$25 \mu \mathrm{g} /$ day) on left ventricular diastolic function in patients with $\mathrm{SCH}$.

At baseline, patients with $\mathrm{SCH}$ showed significantly E/A ratio in comparison with healthy controls. After 6 months of therapy, the E/A ratio underwent significant increase. They concluded that treatment with low-dosed L-T4 might improve left ventricular diastolic function in patients with $\mathrm{SCH}^{(35)}$.

\section{CONCLUSION}

It could be concluded that LT4 treatment for women with $\mathrm{SCH}$ was found to improve total clinical thyroid score, HR-QOL, systolic and diastolic dysfunction besides lowering TC, LDL and TG levels. However, there was evidence of bone loss in patients with SCH treated with L-T4. Thus, decision to treat or not to treat should be individualized according to the patient's risk benefit ratio assessment.

Study limitations include small sample size of the study subjects, besides assessing autoimmune thyroid antibodies qualitatively rather than 
quantitatively. We recommend long-term studies on wider scale to confirm our results.

\section{REFERENCES}

1. Feller M, Snel M, Moutzouri E et al. (2018): Association of Thyroid Hormone Therapy with Quality of Life and Thyroid-Related Symptoms in Patients with Subclinical HypothyroidismA Systematic Review and Meta-analysis. JAMA., 320(13):1349-1359.

2. Pearce S, Brabant G, Duntas L et al. (2013): ETA Guideline: Management of Subclinical Hypothyroidism. Eur Thyroid J., 2(4): 215-28.

3. Pesic M, Radojkovic D, Antic S et al. (2015): Subclinical hypothyroidism: association with cardiovascular risk factors and components of metabolic syndrome. Biotechnol Biotechnol Equi., 29(1): 157-63.

4. Pyati A, Dhuttargi S and Das D (2012): Assessment of the Cardiovascular Risk in Subclinical Hypothyroidism. Int J Pharm BiolSci., 2(2):128-134.

5. Karmisholt J, Andersen $S$ and Laurberg $P$ (2011): Variation in thyroid function in subclinical hypothyroidism: importance of clinical follow-up and therapy. Eur J Endocrinol., 164(3): 317-23.

6. Li M and Tang $Z$ (2015): Subclinical hypothyroidism: to treat or not to treat? Med PrincPract. Karger Publishers.

7. Zhao M, Tang X, Yang T et al. (2015):Lipotoxicity, a Potential Risk Factor for the Increasing Prevalence of Subclinical Hypothyroidism? J Clin Endocrinol Metab., 100(5): 1887-94.

8. Andersen M, Olsen A, Madsen J et al. (2015): Levothyroxine Substitution in Patients with Subclinical Hypothyroidism and the Risk of Myocardial Infarction and Mortality. PLoS One. Public Library of Science, 10(6): 1293-97.

9. Walsh J, Ward L, Burke V et al. (2006): Small Changes in Thyroxine Dosage Do Not Produce Measurable Changes in Hypothyroid Symptoms, WellBeing, or Quality of Life: Results of a Double- Blind, Randomized Clinical Trial. J Clin Endocrinol Metab., 91(7): 2624-30.

10. Khandelwal $D$ and Tandon $N$ (2012): Overt and subclinical hypothyroidism: who to treat and how. All India Institute of Medical Sciences, New Delhi, India, Drugs, 72(1): 17-33.

11. Heneryk Z, Beat M, Pascale E et al. (1997): Estimation of Tissue Hypothyroidism by a New Clinical Score: Evaluation of Patients with Various Grades of Hypothyroidism and Controls.Journal of Clinical Endocrinology and Metabolism, 82(3): 132-135.

12. Reuters V, Almeida $C$, Teixeira $P$ et al. (2012): Effects of subclinical hypothyroidism treatment on psychiatric symptoms, muscular complaints, and quality of life. Arq Bras Endocrinol Metab., 56(2):128-36.

13. Martins R, Fonseca $R$, Duarte $M$ et al. (2012): Impact of subclinical hypothyroidism treatment in systolic and diastolic cardiac function: errata. Arq Bras Endocrinol Metabol., 56(1):74-80.
14. Lang R, Michelle B, Richard B et al. (2005): Recommendations for Chamber Quantification. Journal of the American Society of Echocardiography, 18(12): 1440-1463.

15. Plewka M, Krzemińska $M$ and Drozdz J (2005): Tissue Doppler echocardiographic identification of ischemic etiology in patients with dilated cardiomyopathy. Scand Cardiovasc J., 39(6):334-341.

16. Gupta G, Sharma P, Kumar $P$ et al. (2015): A correlation between thyroid stimulating hormone and body mass index in women with subclinical hypothyroidism. Asian J Pharm Clin Res., 8(4): 206-208.

17. Karthick N, Dillara K, Poornima K et al. (2013): Dyslipidaemic changes in women with subclinical hypothyroidism. J Clin Diagn Res., 7:2122-5.

18. Ito M, Kitanaka A and Arishima T (2013): Effect of Lthyroxine replacement on apolipoprotein B-48 in overt and subclinical hypothyroid patients. Endocr J., 60: 6571.

19. Pandrc M, Risti A, Kostovski V et al. (2017): The effect of early substitution of subclinical hypotheroidism on biochemical blood parameters and the quality of life.J Med Biochem., 36: 127-136.

20. Jorde $R$, Waterloo $K$ and Storhaug $H$ (2006): Neuropsychological function and symptoms in subjects with subclinical hypothyroidism and the effect of thyroxine treatment. J Clin Endocrinol Metab., 91:145153.

21. Joffe RT, Pearce EN, Hennessey JV et al. (2013): Subclinical hypothyroidism, mood, and cognition in older adults: a review. International Journal of Geriatric Psychiatry, 28(2):111-8.

22. Meier C, Miserez R, Drewe J et al. (2014): TSHControlled L-Thyroxine Therapy Reduces Cholesterol Levels and Clinical Symptoms in Subclinical Hypothyroidism. Osteoporos Int., 15:209-16.

23. Baumgartner $\mathbf{C}$, Blum $\mathbf{R}$ and Rodondi $\mathbf{N}$ (2014): Subclinical hypothyroidism: summary of evidence. Swiss Med Wkly., 144:158.

24. Klaver E, Hannah C, Riejanne S et al. (2013): Thyroid Hormone Status and Health-Related Quality of Life in the Life Lines Cohort Study. Thyroid, 23(9):1066-73.

25. Bianchi G, Zaccheroni $\mathrm{V}$, Solaroli $\mathrm{E}$ et al. (2014): Health-related quality of life in patients with thyroid disorders. Quality Life Res., 13(1): 45-54.

26. Murphy E, Glïer C and Reid D (2010): Thyroid function within the upper normal range is associated with reduced bone mineral density and an increased risk of non-vertebral fractures in healthy euthyroid postmenopausal women. J ClinEndocrinol Metabolism, 95(7): 3173-3181.

27. Garin M, Arnold A, Lee J et al. (2014): Subclinical thyroid dysfunction and hip fracture and bone mineral density in older adults: the cardiovascular health study. J ClinEndocrinol Metabolism, 99:2657-64.

28. López P, López C, Naharro F et al. (2011): Osteoporosis in patients with subclinical hypothyroidism treated with thyroid hormone Clinical Cases in Mineral and Bone Metabolism, 8(3): 44-4. 
29. Swathi K, Haseena S and Hussain S (2014): Effect of TSH Suppression Therapy on Bone Density in Hypothyroidism. J. Pharm. Sci. \& Res., 6(2): 104-111.

30. Tognini S, Polini A and Pasqualetti G (2012): Age and gender substantially influence the relationship between thyroid status and the lipoprotein profile: results from a large cross-sectional study. Thyroid, 22:1096-1103.

31. Kota S, Meher L, Krishna $\mathrm{S}$ et al. (2012):Hypothyroidism in metabolic syndrome. Indian J Endocrinol Metabolism, 16(2): 332-333.

32. Caraccio N, Ferrannini $\mathbf{E}$ and Monzani $\mathbf{F}$ (2002):Lipoprotein profile in subclinical hypothyroidism: response to levothyroxine replacement, a randomized placebo-controlled study. J ClinEndocrinolMetab., 87:1533-1538.
33. Anagnostis $\mathrm{P}$, Efstathiadou $\mathrm{Z}$, Slavakis $\mathrm{A}$ et al. (2014): The effect of L- thyroxine substitution on lipid profile, glucose homeostasis, inflammation and coagulation in patients with subclinical hypothyroidism. Int J Clin Pract., 68(7): 857-63.

34. Preethi J and Sripriya $H$ (2018): Echocardiographic Changes in Overt and Subclinical Primary Hypothyroidism. International Journal of Scientific Study, 6: 2321-595.

35. Shatynska M, Rodrigo $\mathrm{L}$, Cioccocioppo $\mathrm{L}$ et al. (2015): The impact of thyroid hormone replacement therapy on left ventricular diastolic function in patients with subclinical hypothyroidism. J Endocrinol Invest., 39(6):709-713. 